\title{
Syringomyelia - a complication of meningitis - case report
}

\author{
A Kakar, VS Madan and V Prakash \\ Department of Internal Medicine and Neurosurgery, Sir Ganga Ram Hospital, Rajinder Nagar, New Delhi-60, India
}

Syringomyelia following meningitis is a rare condition. This report summarizes the history of a 43 year old Indian male who developed arachnoiditis as a sequalae of tubercular meningitis. This later progressed to syringomyelia. The patient was treated with a syringo-subarachnoid shunt.

Keywords: tuberculous meningitis; arachnoiditis; syringomyelia

\section{Introduction}

Syringomyelia is a rare condition with many possible aetiologies. In the 'Non hind brain related Syrinx', syringomyelia as a complication of meningitis is well known. We here describe a patient who developed post meningitic arachnoiditis and this later resulted in the development of syringomyelia.

\section{Case report}

A 43 year old male was admitted to us with the history of low backache in July, 1992, and was diagnosed as having a protrusion of an intervertebral disc, and was given an epidural injection of steroids with a long acting anaesthetic. In August 1992, he became drowsy and had neck rigidity. The lumbar puncture findings were suggestive of pyogenic meningitis. He received antibiotics for 11 days prior to discharge. The patient was readmitted after 5 days with headache and fever. Repeat lumbar puncture findings suggested a tuberculous infection with a sub-arachnoid block. ELISA for tuberculosis was positive. The patient received antitubercular drugs with steroids.

In January 1993, the patient presented with tetraparesis. There was hypertonia, grade 4 motor power in all of the limbs, brisk deep tendon reflexes and extensor plantar responses. There was sensory loss up to T5-6. CSF examination was suggestive of a spinal sub-arachnoid block. Cervical myelography showed arachnoiditis with a partial block at T8-9. Cervical MRI revealed swelling of cord from $\mathrm{C} 4-7$ with pooling of CSF from the foramen magnum up to C3 level (Figure 1). Laminectomy was done at C3-7 level. The thickened and opaque arachnoid was excised from the posterior aspect of cord using microsurgical techniques. The histopathological report was consistent with chronic arachnoiditis.
From February 1993 to July 1995 the patient was asymptomatic and the neurological deficit regressed considerably. Antituberculous treatment was given for 18 months. In October 1995, he was readmitted with a gradually increasing tetraparesis, numbness in both hands and the trunk for 2 previous months. Motor power in right upper and left lower was grade 4.

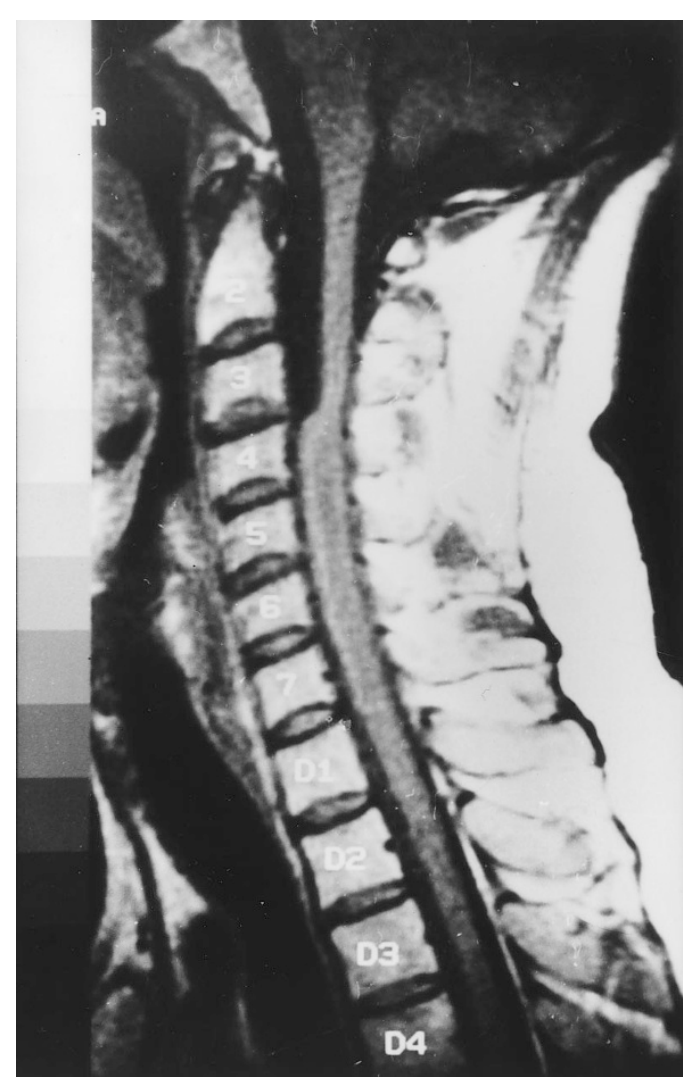

Figure 1 MRI cervico dorsal spine, January 1993, T1weighted image showing arachnoiditis 
Upper limb reflexes were diminished bilaterally and left ankle jerk was absent. Plantar reflexes were flexor. There was decreased pinprick sensation at the C6-8 level with decreased hot and cold sensation in the right hand. Posterior column sensations were lost in both upper limbs. MRI study showed arachnoiditis from $\mathrm{C} 4-7$ level, syrinx formation C5-T11 level and thinning of cord at C2-5 level (Figure 2). Syringoperitoneal shunt was planned but at the site of laminectomy (T5-6), the arachnoid appeared normal and there was free flow of CSF hence a syringosubarachnoid shunt was done. At present, 8 months after surgery, the patient has a residual neurological deficit in the form of right grip and left lower limb weakness (grade 4+). Despite the weakness, he is able to write and to attend to his daily activities independently. The patient is still being followed up.

\section{Discussion}

Spinal arachnoiditis occurring during or after tuberculous meningitis continues to be a commonly encountered problem in developing countries. ${ }^{1}$ Our patient

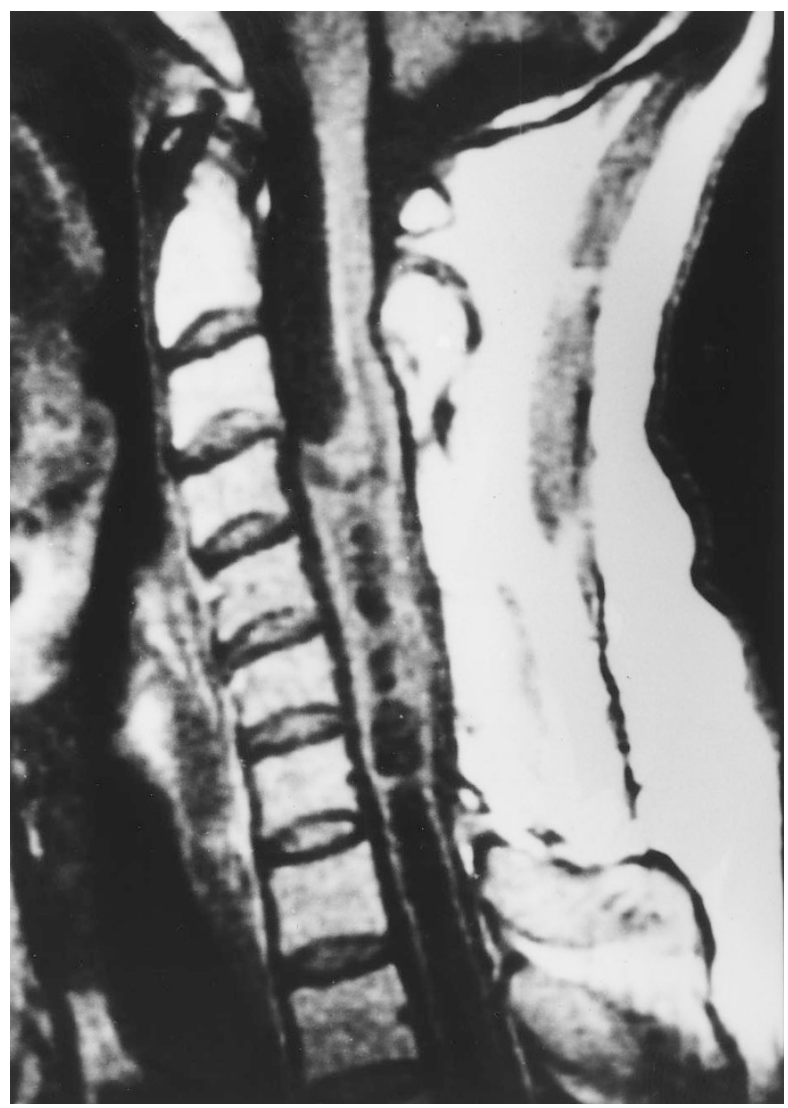

Figure 2 MRI cervical spine, October 1995, preoperative. $\mathrm{T} 1$-weighted image showing irregular dilatation of the central canal-syrinx with abnormal soft tissue density overlying the spinal cord-arachnoiditis received a full course of antituberculous treatment and despite that he continued to deteriorate to form a syrinx. Such presentations are well known despite therapy. ${ }^{2}$ The antituberculous treatment has decreased the mortality significantly but has failed to decrease complications such as spinal arachnoiditis. On the contrary, the incidence of the latter condition has increased. $^{3}$ Arachnoiditis, in turn, can modify the efficacy of antitubercular drugs especially early in the course of the disease by restricting the circulation of CSF. This may account for therapeutic failure and increased mortality. ${ }^{4}$

The cause of the initial cavity in syringomyelia secondary to arachnoiditis is obscure. Various factors have been implicated in the pathophysiology. Barnett ${ }^{5}$ and Mackay ${ }^{6}$ have described severe vascular changes leading to cord ischaemia. The most severe changes are in the segments supplied by the anterior spinal artery and arterial boundaries between the anterior and posterior arteries. These areas include the central region of the spinal cord, anterior horns, the crossing spinothalamic fibres and the corticospinal tracts. Ischaemia leads to softening of the cord and these areas coalesce to form a cavity. ${ }^{7}$ The scarring of arachnoiditis that follows the meningitic process can be localized or diffuse. The scarred meninges results in shearing stress and disruption of tissue planes with subsequent release of fluid into the tissues. ${ }^{8}$ The altered mechanics and pressure could force CSF into the central canal and cause its expansion. ${ }^{7}$ Obstruction to the Virchow Robin spaces also, is a known factor. These perivascular spaces are dilated due to the increased pressure of the spinal CSF. By coalescence of such small pools of extracellular fluid, a true syrinx could eventually be formed. ${ }^{9}$ Venous congestion, cord ischaemia and transport of fluid along the perivascular spaces may all contribute to the maintenance of cord cavities with resulting clinical disabilities.

The latent period between the initial inflammatory events and the development of symptoms is usually long and varies between $7-23$ years. ${ }^{7}$ In our patient this was relatively short and was 5 months. Acute presentation has also been described. ${ }^{10}$ The cause of this rapidly progressive myelopathy in tuberculous cases has been attributed to vascular thrombosis of spinal cord vessels. ${ }^{14}$ The classically described sensory loss was not seen in our patient. Milhorat et al in a recent study using MRI found eccentric cavities due to arachnoiditis to have less clinico pathological correlation than central cavities. ${ }^{11}$

The results of treatment of arachnoiditis are usually unrewarding. Intrathecal hyaluronidase has been found efficacious in some studies from India. ${ }^{3,12}$ It acts by hydrolysing the glycosaminidic bands of hyaluronic acid and some other mucopolysaccharides of the ground substance and enhances exudate absorption. However, it is not being used commonly in all centres. In the surgical management of syringomyelia, syrinx to extrathecal shunting is preferred to shunts to the subarachnoid space. ${ }^{13}$ In 
our patient, we opted for a syringo-subarachnoid shunt as the arachnoid was relatively normal at that site and free flow of CSF could be obtained. To conclude, we would recommend serial follow-up MRI for patients with arachnoiditis in order to detect early syringomyelia.

\section{References}

1 Tandon PN. Tuberculous meningitis (cranial and spinal). In: Vinken PJ and Bruyn GW (eds), Klawns HW. Handbook of Clinical Neurology, Infections of the Nervous system, Part I, vol 33, North-Holland Publishing Co: 1978, p 195.

2 Gimenez-Roldan S, Esteban A and Benito C. Communicating syringomyelia following cured tuberculous meningitis. J Neurol Sci 1974; 23: $195-197$.

3 Gouri-Devi M, Padmini R and Satish P. Use of intrathecal hyaluronidase in spinal arachnoiditis complicating tuberculous meningitis. Indian J Med Res 1980; 71: 581 - 593.

4 Brooks WDW, Fletcher AP and Wilson RR. Spinal cord complications of tuberculous meningitis. $Q \mathrm{~J} \mathrm{Med} \mathrm{1954;} \mathrm{23:} 275$.
5 Barnett H. Syringomyelia associated with spinal arachnoiditis. In: Barnett $\mathrm{H}$, Foster J, Hudgson P (eds). Syringomyelia. London: Saunders, 1973, pp. 220-260.

6 Mackay R. Chronic adhesive spinal arachnoiditis. JAMA 1939; 112: $802-808$.

7 Caplan LR, Norohna AB and Amico LL. Syringomyelia and arachnoiditis. J Neurol Neurosurg Psychiatry 1990; 53: 106-113.

8 Williams B. On the pathogenesis of syringomyelia: a review. $J$ Roy Soc Med 1980; 73: $798-806$.

9 Ball MJ and Dayan AD. Pathogenesis of syringomyelia. Lancet 1972; 2: $799-801$.

10 Schapira $\mathrm{M}$ et al. Acute paraplegia and intramedullary cavitation in a patient with pulmonary tuberculosis. Medicine B Aires 1992; 52: $560-562$.

11 Milhorat TH et al. Clinicopathological correlation in syringomyelia using axial magnetic resonance imaging. Neurosurg 1995; 37: $206-213$.

12 Gouri-Devi $M$ and Satish P. Enzyme therapy of spinal arachnoiditis - potential usefulness of hyaluronidase. Curr Sci 1979; 48: $1017-1019$.

13 Williams B. Progress in syringomyelia. Neurolog Res 1986; 8: $130-145$.

14 Fehlings MG and Bernstein M. Syringomyelia as a complication of tubercular meningitis. Can J Neurol Sci 1992; 19: 84-87. 